\title{
How transformation expectation leads consumers to immediate gratification - A PLS-SEM approach \\ Research-in-Progress
}

\author{
Yiqing Yu \\ Sun Yat-sen University \\ yuyiqing@sysu.edu.cn
}

\author{
Qinghua Zhu \\ Nanjing University \\ qhzhu@nju.edu.cn
}

\begin{abstract}
This study explores the mechanism which triggers consumer's immediate gratification behavior. It is proposed that consumer's expectation of meaningful life transformation by acquisition of a product causes her perception of product hedonic and utilitarian value, which can further predict immediate gratification. The positive impact of perception of hedonic value on immediate gratification can be mediated by price sensitivity and moderated by materialism level. The structural model is established for further empirical analysis with PLSSEM approach. The model suggests different domain of transformation expectation may have conflicting impact on immediate gratification.
\end{abstract}

Keywords: Expectation, Immediate gratification, Materialism, Price sensitivity, Perception, PLS.

\section{Introduction}

Would you spend two thirds of your monthly income on an iPhone 6 to replace the still well functioning Samsung Galaxy acquired 1 year ago? Quite a few consumers in some countries probably would, and did. Why would they, regardless of the poor affordability, pursue immediate gratification in a way that they will suffer financial insecurity next month? What do they expect from the purchase? This type of purchase behavior epitomizes consumer's desire for buying, and more specific, possession, because they believe that their lives will be changed in a significant and meaningful way by the acquisition and use of a product. This is exactly the definition of transformation expectation (Richins, 2011, p. 145). Every consumer may have transformation expectation of possession regardless of her purchase-orientation. Such a possession-based orientation is coined materialism, which is defined by Belk (1984, p. 291) as " ...the importance a consumer attaches to worldly possessions... ". One of the negative consequences of materialism is self-control failure (Fitzmaurice, 2008). From the cognitive perspective it has been empirically evidenced that materialistic thoughts undermine self-control through low level construal (Kim, 2013). It is indeed a comprehensive and extensive approach, but somewhat abstract and hence impractical to address a specific scenario, such as consumer's immediate gratification behavior, as no purchasing-related factors were considered. Therefore, it is necessary to incorporate them into the justification of the cause of immediate gratification and model the consumer's cognitive process. This research seeks to address this gap and further contrast the predictive power of consumer's expectation of possession between high and low level materialists. We begin with investigating the influence of individual's transformation expectation on the perception of product attributes. Next, we link the perception of production attributes to the perception of 
price which ultimately predicts immediate gratification. In the end we examine the moderating role of materialism on this relationship.

The present study aims to predicatively investigate immediate gratification, which serves as the primary reason for employing PLS-SEM approach. We establishes structural model to shed light on the causal relationship between transformation expectation and consumer's immediate gratification, and how this relationship differs across the high and low level materialists. The present study theoretically advances the Kim's model (Kim, 2013) to the real purchase setting, and facilitates a subsequent empirical investigation.

\section{Understanding perceived product attributes}

Product value is a subjective concept that is highly contingent on consumers' evaluation of and attitudes toward the product. As a purchase behavior is triggered by utilitarian and hedonic considerations, consumers probably assign more hedonic value to some products which are considered as hedonic goods, while more utilitarian value to others which are considered as utilitarian goods. In general, hedonic goods provide more experiential consumption, fun, pleasure, and excitement such as designer sunglasses, souvenirs, sports cars, etc., whereas utilitarian goods are primarily instrumental and functional, such as tissue, baking oven, etc. (Strahilevitz \& Myers, 1998). Notice that the value of any product for a specific consumer could be a combination of the two values. A hedonic good could have utilitarian value for the consumer and vice versa. A consumer's purchase decision for a watch is primarily based on its precision and design as well. In this sense, the watch has both hedonic and utilitarian value for the consumer. Which value is more weighted depends on consumer's usage and consumption motives (Khan, Dhar, \& Wertenbroch, 2004), namely to what extent she expects the product to transform her life. Thus, we can propose that perceived product value can be predicted by consumer's transformation expectation. Grounded on this proposition, we can further distinguish between hedonic and utilitarian value and identify which domain of transformation expectation contributes to hedonic value and which to the utilitarian one.

Richins (2011) has validated that transformation expectation can be neatly classified into four categories, which are mutually exclusive. First, by acquiring the desired object, consumer expects transformation of the Self and other's perceptions of the Self, which can be reflected by improving self-regard and self-confidence, or realizing sense of achievement. Apparently such transformation has little to do with the product functions, but hedonic attributes instead. Second, consumer expects relationship transformation which refers to positive changes in interpersonal relationships ascribed to an acquisition. The cases, such as bigger house to entertain more guests, or perfume to keep a closer distance with lovers, demonstrate that such expectation is affective, and can satisfy human's need to bond, far beyond the instrumental functions of the product. Third, consumer expects hedonic transformation which implies significant increase of positive emotions such as pleasure, excitement, peacefulness and fun. It is usually evoked by sensory experience such as taking a ride on a mountain bike or swimming in a private swimming pool. It is self-evident that these experiences are more likely to be related to hedonic value than utilitarian value (in the case of mountain bike, it is not just a tandem of two tires fixed by a metal frame). These 3 domains of transformation expectation are arguably associated with perceived hedonic value. The cause-effect relationship between them can be further inferred from psychology: Perception is not the passive receipt of the signals resulting from physical or chemical stimulation of the sense organs. Instead, it is shaped by learning, memory, expectation, and attention (Bernstein \& Nash, 2005) . Expectation's influence on perception is characterized by top-down processing 
of sensory input (Coon \& Mitterer, 2012). Therefore we argue consumer's transformation expectation influences perceived product value, and not the other way around. Taken together, we propose:

H 1/2/3: Consumer's expectation of self /relationship/ hedonic transformation has a positive impact on perceived hedonic value. (Fig. )

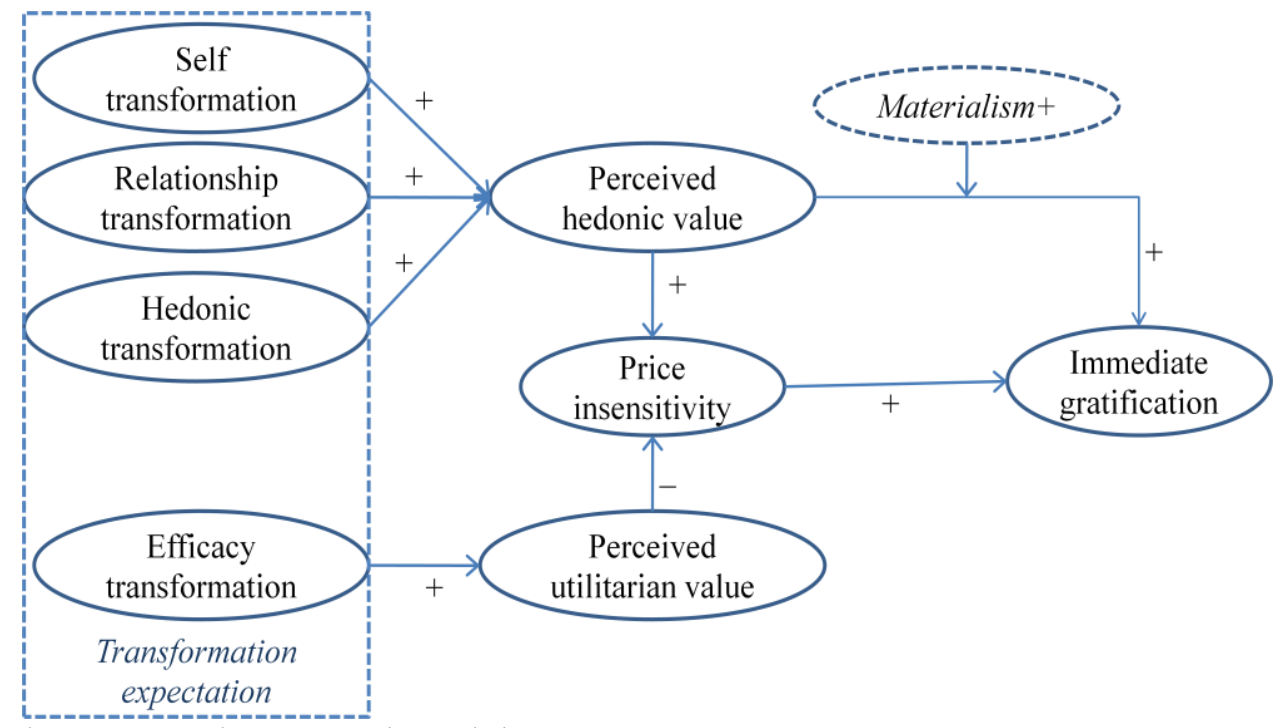

Figure: The proposed structural model

Additionally, as Richins (2011) indicated, consumer expects efficacy transformation. For example, contact lens facilitates doing vigorous exercises such as hockey; a home cleaning robot is not only time-saving but relieves physical burden and makes life less strenuous. Efficacy transformation involves a greater control over one's life and is characterized by convenience or effectiveness. It differs from the aforementioned 3 domains in arousal effect of consumer's perception. In order to get oneself more adapted to the environment and minimize the friction loss during the interaction with the physical world, consumer is more likely to consider the desired product as a facilitator or instrument. Accordingly, it is proposed:

$\mathrm{H}$ 4: Consumer's expectation of efficacy transformation has a positive impact on perceived utilitarian value. (Fig.)

\section{The perception of product attributes and price sensitivity}

Price sensitivity refers to the extent to which individuals perceive and respond to changes or differences in price for products or services (Monroe, 1973). Wakefield and Inman (2003) have found out that: the more hedonic the perceived consumption occasion for a product, the less the price elasticity, and this relationship is attenuated by higher income for hedonic consumption occasions. Please note that in their survey respondents evaluated the use situation on seven-point scales with the anchors like "practical purposes-just for fun", "purely functional-pure enjoyment", and "for a routine need - for pleasure". Apparently, they handled and measured the hedonic and functional nature of the product on a single scale instead of dichotomizing the perception of hedonic and utilitarian value. We argue that it is essential to distinguish the measurement of two perceptions because there are evidences that the positive affective feelings are not the bipolar opposite of negative affective feeling, i.e. they can be independent of each other (Egloff, 1998). As Diener and Iran-Nejad (1986) indicated, if one type of affect is at low intensity, the other type can be at any level from low to high. By the 
same token, given the connectedness between hedonic vs. utilitarian goods and affect-rich vs. affect-poor ones (Khan et al., 2004), consumer can arguably have intensive perception of both hedonic and utilitarian value. This case was, however, completely neglected in Wakefield and Inman's survey due to the one-dimensional measurement scales. In view of this, we examine this relationship (consumer's perception of product attributes $\rightarrow$ price sensitiveness) in a refined way by measuring the perceptions of hedonic value and utilitarian value independently as two latent constructs.

Additionally, we investigate price sensitivity (1) by controlling income (Wakefield \& Inman, 2003); (2) in a reversed way, because it is common sense to propose a positive influential effect on the predicted variable- immediate gratification, since the present study ultimately examines what predicts it. Taken together, the following hypotheses are proposed (Fig.) :

H5: Consumer's perceived hedonic value has a positive impact on her insensitivity to price.

H6: Consumer's perceived utilitarian value has a negative impact on her insensitivity to price.

\section{Immediate gratification and the mediating role of price insensitivity}

As the introductory case describes, if the consumer purchases iPhone 6 , she gains immediate reward (e.g. improved mood) and delayed cost (e.g. the financial plan for next several months will be messed up). Considering that a delayed reward (financial security in, say, next 5 months) is less certain than an immediate reward, she succumbs to such temptation, despite knowing it will incur financial insecurity later. She pursues immediate gratification in a way that she herself may not appreciate in the long run. As Daugherty and Brase (2010) indicated, higher levels of hedonism suggest stronger tendencies to seek out pleasure in the present. Higher levels of hedonism, in parallel, imply an acute sense of product's hedonic value. Thereby, we propose:

H7: Perceived hedonic value has a positive impact on immediate gratification. (Fig.)

Based on $\mathrm{H7}$, we further explore how perceived hedonic value might lead to immediate gratification. As proposed by H5, consumer's sensitivity to the price may to some extent mirror her perception of product attributes. Thereby, we further examine the role of price insensitivity and propose that it explains immediate gratification:

H8: Price insensitivity mediates the relationship between perceived hedonic value and immediate gratification.

\section{The moderating role of materialism}

According to the definition of materialism, possessions assume a central place in a materialist's life. A possessive person should be "concerned with the loss of possession, prefer the greater control of objects, and inclined to save and retain possessions rather than discard them. (Belk, 1984, p. 291)". Furthermore, Richins and Dawson (1992) measured and validated materialism construct from 3 dimensions: (1) Materialists place possessions at the center of their lives; (2) They view possessions as essential to their satisfaction and wellbeing in life; (3) They judge their own and others' success by the number and quality of possessions accumulated. We can infer from these descriptions that, ceteris paribus, consumer's perception of hedonic value is more likely to elicit real purchase behavior for high-level materialists than their low counterparts as they attach more importance to 
possession and acquisition. Hence, it is worth testing:

H7a: The relationship between perceived hedonic value and immediate gratification is reinforced (attenuated) by high (low) -level materialists. (Fig.)

\section{Methodology and implication}

The measurement models of constructs "transformation expectation" and "materialism" will be adapted from the validated scales by Richins (2011) and Richins and Dawson (1992). "Price sensitivity" will be measured based on the reversed form of scales proposed by Wakefield and Inman (2003). Since they are all measured reflectively, the consistent PLS (PLSc) will be used to overcome consistency problem (Dijkstra \& Henseler, 2015). "Perceived hedonic/ utilitarian value" will be measured in a formative way because it is interesting to identify which domain of perception of hedonic/utilitarian value predicts/ attenuates immediate gratification, e.g. does the improvement of consumer's social status, or of appearance contribute to her immediate purchase? In view of the two formative constructs, it is a composite factor model which can be clearly estimated by PLS (Henseler et al., 2014). By virtue of the fact that this model is not to test and confirm any ready-made theory about the impact of transformation expectation on immediate gratification, this is a predictionoriented model. Such features of the present work are the evidence that PLS-SEM is the appropriate approach (Hair Jr, Hult, Ringle, \& Sarstedt, 2014).

Upon the structural model of the present study, we argue that the impact of transformation expectation on immediate gratification is the consequence of the counterbalance: with self/ relationship/ hedonic transformation expectation eliciting immediate gratification while efficacy one suppressing it. We also expect the survey data will support this proposition.

\section{References}

Belk, Russell W. (1984). Three scales to measure constructs related to materialism: Reliability, validity, and relationships to measures of happiness. Advances in Consumer Research, 11(1), 291-297.

Bernstein, Douglas A., \& Nash, Peggy Wright. (2005). Essentials of psychology (3rd ed.). Boston: Houghton Mifflin.

Coon, Dennis, \& Mitterer, John O. . (2012). Introduction to psychology : gateways to mind and behavior (13th ed.): Cengage Learning.

Daugherty, James R., \& Brase, Gary L. (2010). Taking time to be healthy: Predicting health behaviors with delay discounting and time perspective. Personality and Individual Differences, 48, 202-207. doi: 10.1016/j.paid.2009.10.007

Diener, E., \& Iran-Nejad, A. (1986). The relationship in experience between various types of affect. Journal of Personality and Social Psychology, 50(5), 1031-1038. doi: 10.1037/0022-3514.50.5.1031

Dijkstra, Theo K., \& Henseler, Jörg. (2015). Consistent Partial Least Squares Path Modeling. MIS Quarterly, 39(2).

Egloff, Boris. (1998). The independence of positive and negative affect depends on the affect measure. Personality and Individual Differences, 25(6), 1101-1109. doi: http://dx.doi.org/10.1016/S0191-8869(98)00105-6

Fitzmaurice, Julie. (2008). Splurge purchases and materialism. Journal of Consumer Marketing, 25(6), 332-338. doi: doi:10.1108/07363760810902468

Hair Jr, Joseph F., Hult, G Tomas M., Ringle, Christian, \& Sarstedt, Marko. (2014). A primer 
on partial least squares structural equation modeling. USA: Sage.

Henseler, J., Dijkstra, T. K., Sarstedt, M., Ringle, C. M., Diamantopoulos, A., Straub, D. W., . . . Calantone, R. J. (2014). Common Beliefs and Reality About PLS: Comments on Rönkkö and Evermann (2013). Organizational Research Methods, 17(2), 182-209. doi: $10.1177 / 1094428114526928$

Khan, Uzma, Dhar, Ravi, \& Wertenbroch, Klaus. (2004). A behavioral decision theoretic perspective on hedonic and utilitarian choice. In S. Ratneshwar \& G. D. Mick (Eds.), Inside Consumption: Frontiers of research on consumer motives, goals, and desires. USA and Canada: Routledge.

Kim, Hyeongmin. (2013). Situational materialism: How entering lotteries may undermine self-Control. Journal of Consumer Research, 40(4), 759-772. doi: 10.1086/673191

Monroe, Kent B. (1973). Buyers' subjective perceptions of price. Journal of Marketing Research, 10(1), 70-80.

Richins, Marsha L. (2011). Materialism, transformation expectations, and spending: Implications for credit use. Journal of Public Policy and Marketing, 30(2), 141-156. doi: 10.1509/jppm.30.2.141

Richins, Marsha L., \& Dawson, Scott. (1992). A consumer values orientation for materialism and its measurement: scale development and validation. Journal of Consumer Research, 19(3), 303-316.

Strahilevitz, Michael, \& Myers, John G. (1998). Donations to charity as purchase incentives: How well they work may depend on what you are trying to sell. Journal of Consumer Research, 24(4), 434-446.

Wakefield, Kirk L., \& Inman, J. Jeffrey. (2003). Situational price sensitivity: the role of consumption occasion, social context and income. Journal of Retailing, 79(4), 199212. doi: 10.1016/j.jretai.2003.09.004 